\title{
NEUTRALIZATION OF INFUSED ACID BY NEPHRECTOMIZED DOGS ${ }^{1}$
}

\author{
By ROY C. SWAN ANd ROBERT F. PITTS wIth THE TECHNICAL ASSISTANCE of \\ HARRY MADISSO
}

(From The Department of Physiology, Cornell University Medical College, New York, N. Y.)

(Submitted for publication August 30, 1954; accepted September 22, 1954)

From 8 to $15 \mathrm{mM}$ of strong mineral acid per kilogram of body weight may be infused intravenously in the dog over a period of a few hours to produce a severe but non-fatal acidosis. Van Slyke and Cullen (1) showed that only one-sixth of the infused acid is neutralized by blood buffers, five-sixths presumably being neutralized by bicarbonate in interstitial fluid and lymph and by intracellular phosphate and proteinate buffers. Recently, Bergstrom and Wallace(2) have indicated that sodium and potassium on the surface of bone crystals are also available for neutralization of acid.

How tissue buffers participate in the neutralization of acid has been investigated by measuring changes in total quantity of extracellular sodium, potassium, bicarbonate, and chloride ions following infusion of hydrochloric acid into nephrectomized dogs. Our preliminary reports $(3,4)$ were based on experiments in which extracellular fluid volume was approximated by inulin distribution. The observation of a considerable increase in the inulin volume of distribution following infusion of acid led us to compare volumes of distribution of several substances proposed by others as approximations of extracellular fluid volume. This comparison indicated that radiosulfate distribution more closely measures extracellular fluid volume than does inulin in the whole animal (5). Therefore, the experiments on the effects of hydrochloric acid infusion have been repeated using radiosulfate distribution to measure changes in extracellular fluid volume. No definitive publication of the original experiments is contemplated.

The results of our recent experiments indicate that when $10 \mathrm{mM}$ of hydrochloric acid per kilogram of body weight are infused into a nephrectomized dog over a period of two hours, 43 per cent of the infused acid is neutralized by bicarbonate

\footnotetext{
1 Supported by a grant from the American Heart Association.
}

originally present in extracellular fluid, whereas 51 per cent is neutralized by a process in which hydrogen ions are exchanged for sodium and potassium ions which diffuse into extracellular fluid probably from cells. Simultaneously a 16 per cent increase in extracellular fluid volume occurs.

The results of our earlier experiments using inulin agree qualitatively with each of these findings. The results differ quantitatively for the volume of distribution of inulin is less than that of radiosulfate (5), and in our earlier experiments correction was not made for the slow disappearances of inulin after two to three hours of equilibration.

\section{EXPERIMENTAL PLAN}

Dogs were nephrectomized immediately before an experiment to eliminate renal excretion of acid and to measure more accurately the volume of distribution of radiosulfate. Control values for sodium, potassium, bicarbonate, and chloride in extracellular fluid and in the circulating erythrocyte mass were established three and four hours after nephrectomy. One and one-half and two and one-half hours after the production of a severe metabolic acidosis by hydrochloric acid infusion the total amounts of these ions in the extracellular fluid and in the erythrocyte mass were re-established. Ion shifts into or out of the extracellular fluid and circulating erythrocyte mass were calculated from the differences in mean ion contents observed in the two control and two acidosis observations.

Four control experiments were performed under conditions comparable except that in three acid was not infused, and in one only 3 per cent glucose was infused in a volume comparable to the volume of the acid infusions.

\section{EXPERIMENTAL PROCEDURE}

Healthy, moderately lean, adult male dogs were lightly anesthetized with sodium pentobarbital, weighed and nephrectomized bilaterally. Radiosulfate $\left(\mathrm{S}^{35} \mathrm{O}_{4}\right)$ and (in two of five experiments) radiochloride $\left(\mathrm{Cl}^{26}\right)$ were infused as previously described (5). Two and one-half, three, three and one-half and four hours after infusion of radioisotopes arterial blood samples were drawn for measurement of plasma radiosulfate concentration and 
plasma specific gravity. Additional samples were obtained at three and four hours for plasma and whole blood sodium, potassium, $\mathrm{CO}_{2}$, chloride and for plasma radiochloride and inorganic phosphate concentrations, plasma $\mathrm{pH}$, whole blood water content and hematocrit. Following the four-hour blood sampling, $0.3 \mathrm{~N} \mathrm{HCl}$ totalling approximately $10 \mathrm{mM}$ per $\mathrm{Kg}$. of body weight was infused simultaneously through each of two polyethylene catheters, one inserted through a femoral vein into the inferior vena cava, the other inserted through an external jugular vein into the superior vena cava. Acid was infused at a rate of $2 \mathrm{ml}$. per minute through each of the catheters.

One hour following completion of the infusion of acid and at half-hour intervals thereafter, four arterial blood samples were drawn for plasma radiosulfate concentration and plasma specific gravity. Additional samples were drawn at one and one-half and two and one-half hours following completion of the acid infusion for plasma and whole blood sodium, potassium, $\mathrm{CO}_{2}$ and chloride and for plasma radiochloride and inorganic phosphate concentrations, plasma $\mathrm{pH}$, whole blood water content and hematocrit. Plasma volume was measured by T-1824 dilution (6) one and one-half hours before the infusion of acid was started and two hours after the infusion was completed.

Approximately $120 \mathrm{ml}$. of blood were drawn before and a similar amount following acid infusion. Autopsy following each experiment verified that renal excretion had been completely eliminated and that hemorrhage at the operative sites had not occurred.

\section{ANALYTICAL METHODS}

Whole blood water content was measured by weighing $1 \mathrm{ml}$. samples and drying at $105^{\circ} \mathrm{C}$. for 24 hours. Plasma water content, hematocrit, plasma radiosulfate and radiochloride concentrations were measured by methods previously described (5). These radioisotopes do not mutually interfere in these methods. Appropriate corrections for self-absorption for radiochloride were applied for changing plasma chloride concentrations. Plasma and whole blood sodium and potassium concentrations in heparinized samples were measured by internal standard flame photometry. Samples for plasma $\mathrm{pH}$ and plasma and whole blood $\mathrm{CO}_{2}$ and chloride were collected anerobically in oiled, oxalated syringes and plasma fractions promptly separated. Plasma $\mathrm{pH}$ was measured at $37^{\circ} \mathrm{C}$. with a water-jacketed Cambridge glass electrode, plasma and whole blood $\mathrm{CO}_{2}$ by the method of Van Slyke and Neill (7) and plasma and whole blood chloride by the method of Van Slyke and Hiller (8). Whole blood chloride was measured in modified Folin-Wu filtrates (9). Plasma inorganic phosphate was measured by a modification of the method of Fiske and SubbaRow (10). All analyses were made in duplicate.

\section{CALCULATIONS}

1. Plasma concentrations have been corrected for plasma water content. Interstitial fluid concentrations

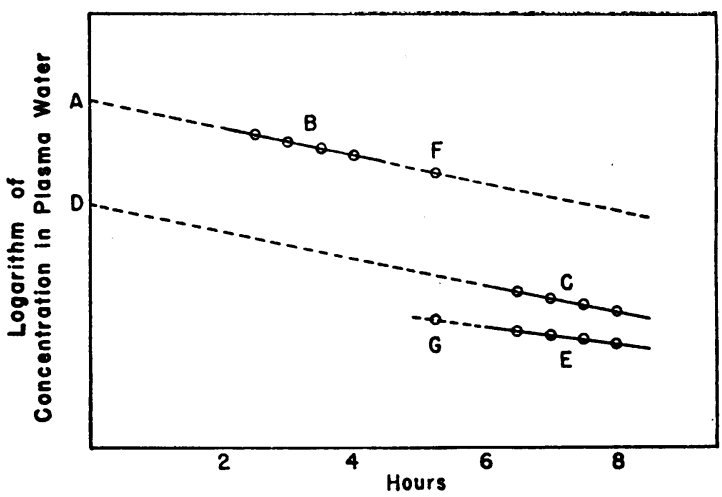

Fig. 1. Calculation of Initial and Final Extracellular fluid Volumes

have been calculated from plasma water concentration by applying a Donnan factor of 0.95 for all monovalent ions. Bicarbonate concentration has been calculated from $\mathrm{CO}_{2}$ concentration and $\mathrm{pH}$ using the Henderson-Hasselbalch equation.

2. Total exchangeable chloride has been calculated by dividing total radiochloride activity injected by plasma specific activity. The radiosulfate volume prior to infusion has been calculated from zero-time concentration (A, Figure 1) obtained by extrapolation of a semilogarithmic plot using a formula (5) which includes correction for plasma volume and Donnan distribution. In all experiments the radiosulfate volume increased following infusion of hydrochloric acid. In two experiments (No. 2, No. 3) the slope of the disappearance curve (B, Figure 1) of radiosulfate remained unchanged after infusion, the curve merely being displaced to a lower range of concentrations ( $C$, Figure 1). In these experiments the radiosulfate volume following infusion has been calculated from the concentration of radiosulfate in plasma water obtained by extrapolating to zero time (D, Figure 1) the disappearance curve obtained after infusion. In the other experiments (No. 1, No. 4, and No. 5) the slope of the disappearance curve (E, Figure 1) decreased slightly following infusion. The post-infusion volume has been calculated by assuming that the slope decreased progressively during and shortly after the infusion. The original curve (B) has been extrapolated to a point midway in time between the two curves. From this concentration $(F)$ and the initial radiosulfate volume total radiosulfate activity in the radiosulfate volume at the midpoint has been calculated. The post-infusion volume has been calculated by extrapolating curve $E$ to the midpoint $(G)$. From this concentration and the total activity, the radiosulfate volume following infusion has been calculated.

3. Concentrations of water, sodium, potassium, and chloride in erythrocytes have been calculated from their plasma and whole blood concentrations and the hematocrit. Erythrocyte bicarbonate concentration has been calculated from the bicarbonate concentration in plasma water and a Donnan factor for chloride derived in each 
experiment from the chloride concentrations in the water of plasma and erythrocytes. (This factor averaged 0.64 in control periods and 0.80 after acid infusion.) Total erythrocyte sodium, potassium, bicarbonate, and chloride have been calculated from their concentrations in erythrocytes and the circulating erythrocyte volume. Circulating erythrocyte volume has been calculated from measured plasma volume and hematocrit. Corrections have not been made for trapped plasma or difference in small and large vessel hematocrit.

\section{RESULTS}

Detailed data from a representative experiment are presented in Table I. The infusion of $161 \mathrm{mM}$ of hydrochloric acid into a $16.8 \mathrm{Kg}$. dog reduced plasma $\mathrm{pH}$ from 7.41 to 7.10 and bicarbonate concentration in plasma water from 24.6 to 7.0 $\mathrm{mM}$ per L. Potassium concentration rose from 4.1 to $10.3 \mathrm{mM}$ per $\mathrm{L}$. The increment in total body chloride (158 $\mathrm{mM}$ ) agrees closely with the amount of chloride infused (161 mM). As a result of the infusion of acid, there was an increase in total extracellular sodium of $55 \mathrm{mM}$ and in potassium of $31 \mathrm{mM}$. Sixty-seven $\mathrm{mEq}$. of base were derived from extracellular bicarbonate as $\mathrm{CO}_{2}$ was eliminated. The increment in extracellular chloride approximates the amount of chloride given as hydrochloric acid despite the observed transfer of $18 \mathrm{mM}$ of chloride into erythrocytes. No significant change in total sodium or potassium in circulating erythrocytes was observed. The rise in hematocrit is in part the result of in- crease in erythrocyte water concentration, but in large part probably due to contraction of the congested spleen of the barbitalized dog.

The results of the five experiments are summarized in Table II. The five dogs, averaging $18.9 \mathrm{Kg}$., received an average of $9.5 \mathrm{mM}$ of hydrochloric acid per $\mathrm{Kg}$. Extracellular fluid volume as measured by radiosulfate distribution, averaging initially 23.6 per cent of body weight, increased an average of $715 \mathrm{ml}$. An average of $615 \mathrm{ml}$. of acid was infused. Thus extracellular fluid volume increased by more than the volume of acid infused. Total sodium in extracellular fluid increased $65 \mathrm{mM}$, equivalent to 36 per cent of infused hydrochloric acid. Total potassium in extracellular fluid increased $28 \mathrm{mM}$, equivalent to 15 per cent of infused hydrochloric acid. Base derived from bicarbonate in extracellular fluid averaged $78 \mathrm{mM}$, equivalent to 43 per cent of infused hydrochloric acid. Total chloride in extracellular fluid increased $170 \mathrm{mM}$. Thus all but 6 per cent of the chloride infused as hydrochloric acid remained in the radiosulfate volume of distribution. Total exchangeable chloride as measured by radiochloride distribution increased by 98 per cent (Exp. No. 4) and 106 per cent (Exp. No. 5) of the chloride given.

In control experiments plasma volume decreased an average of 9 per cent. Plasma $\mathrm{pH}$ increased from an average of 7.40 to 7.43. Hematocrit increased an average of 7 per cent. Total exchange-

TABLE I

Average changes in total millimols of each monovalent ion in extracellular fluid and in circulating erythrocyte mass derived from detailed data from a representative experiment

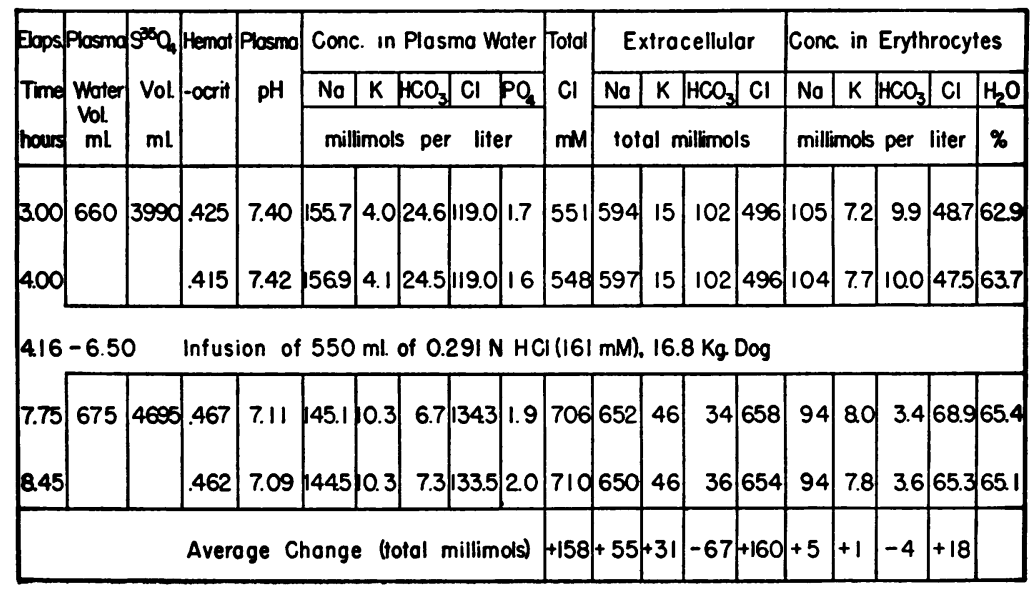


TABLE II

Summary of data from the five experiments

\begin{tabular}{|c|c|c|c|c|c|c|c|c|c|c|c|c|c|c|c|c|c|c|c|}
\hline \multirow{4}{*}{$\begin{array}{c}\text { EXP. } \\
N_{0} \text {. }\end{array}$} & \multirow{4}{*}{$\begin{array}{l}\text { Wt. } \\
\text { Ko. }\end{array}$} & \multicolumn{3}{|c|}{ HCI INFUSED } & \multirow{4}{*}{$\begin{array}{c}\Delta \\
\text { TOTAL } \\
\mathrm{Cl} \\
\mathrm{mM} .\end{array}$} & \multirow{4}{*}{$\begin{array}{c}\Delta \\
\mathrm{s}^{35} \mathrm{O}_{4} \\
\mathrm{VOL} \\
\mathrm{ml} .\end{array}$} & \multirow{4}{*}{$\begin{array}{l}\text { Fimal } \\
\text { prasema }\end{array}$} & \multirow{2}{*}{\multicolumn{4}{|c|}{$\begin{array}{l}\triangle \text { CONG IN } \\
\text { PLASMA WATER }\end{array}$}} & \multirow{2}{*}{\multicolumn{4}{|c|}{$\underbrace{\triangle \text { TOTAL }}_{\text {EXTRACELLLULAR }}$}} & \multicolumn{4}{|c|}{ XHCI NEUTRALIZED BY } \\
\hline & & & & & & & & & & & & & & & & \multirow{2}{*}{\multicolumn{2}{|c|}{$\begin{array}{l}\text { TRANSF. TC } \\
\text { E.C.F. }\end{array}$}} & \multirow{3}{*}{\begin{tabular}{|c|}
$\mathrm{HCO}_{3}$ \\
IN \\
E.C.F.
\end{tabular}} & \multirow{3}{*}{$\begin{array}{l}\text { TRAMS } \\
\text { Of } \\
\text { CI }\end{array}$} \\
\hline & & & man. & VOL. & & & & No & $k$ & $\mathrm{HCO}_{3}$ & $\mid \mathbf{C l}$ & $\mathrm{No}$ & & $\mathrm{HCO}_{3}$ & Cl & & & & \\
\hline & & $\mathrm{mM}$. & $\mathrm{kg}$ & $\mathrm{ml}$. & & & & \multicolumn{4}{|c|}{ millimols per liter } & \multicolumn{4}{|c|}{ millimols } & No & K & & \\
\hline 1 & 18.1 & 190 & 10.5 & 650 & & +765 & 7.09 & -6 & +4 & -16 & +14 & & & & 173 & 46 & 13 & 41 & 9 \\
\hline 2 & 19.0 & 169 & 8.9 & 560 & & +565 & 7.15 & -10 & +5 & $|-18|$ & +14 & & & & 142 & 23 & 16 & 47 & 16 \\
\hline 3 & 20.6 & 189 & 9.2 & 650 & & +755 & 7.05 & -6 & +4 & $\mid-19$ & +19 & & 21 & 14 & 19 & 42 & 11 & 46 & -3 \\
\hline 4 & 16.8 & 161 & 9.6 & 550 & 158 & +705 & 7.10 & -11 & +6 & -18 & +15 & & 31 & -6 & 160 & 34 & 19 & 42 & 1 \\
\hline 5 & 202 & 194 & 9.6 & 665 & 204 & +785 & 6.96 & -9 & +6 & $\mid-16$ & +15 & 18 & +36 & $-78 \mid$ & +182 & 35 & 18 & 40 & 6 \\
\hline Av. & 18.9 & 180 & 9.5 & 615 & & +715 & & -8 & +5 & $\mid-17$ & & & & & +170 & 36 & 15 & 43 & 6 \\
\hline
\end{tabular}

able chloride remained constant. There was no significant change in the calculated total sodium, potassium, bicarbonate, and chloride in extracellular fluid.

Change in total sodium, potassium, bicarbonate, and chloride in circulating erythrocytes after acid infusion averaged $+3 \mathrm{mM}$ (range for the five experiments, -10 to +23$),+1 \mathrm{mM}(-1.2$ to $+2.6),-4(-2.8$ to -6.2$)$ and $+22 \mathrm{mM}$ $(+12$ to +29$)$, respectively. In four control experiments change in total sodium, potas-

TABLE III

Change in osmolarity of plasma water due to monovalent ions and change in anion deficit of plasma water following infusion of acid

\begin{tabular}{|c|c|c|c|c|}
\hline \multirow{2}{*}{$\begin{array}{l}\text { Exp. } \\
\text { No. }\end{array}$} & \multicolumn{2}{|c|}{$\begin{array}{l}\text { milliosmols per liter } \\
\left(\mathrm{Na}+\mathrm{K}+\mathrm{HCO}_{3}+\mathrm{Cl}\right)\end{array}$} & \multicolumn{2}{|c|}{$\begin{array}{l}\text { Anion Deficit (mEq }) \\
\left(\mathrm{No}+\mathrm{K}-\mathrm{HCO}_{3}-\mathrm{Cl}\right)\end{array}$} \\
\hline & Before $\mathrm{HCl}$ & Affer $\mathrm{HCl}$ & Before $\mathrm{HCl}$ & After $\mathrm{HCl}$ \\
\hline 1 & 300.8 & 297.3 & 16.3 & 18.2 \\
\hline 2 & 308.9 & 299.2 & 17.4 & 17.3 \\
\hline 3 & 300.1 & 297.0 & 20.4 & 17.8 \\
\hline 4 & 303.9 & 296.0 & 16.8 & 14.2 \\
\hline 5 & 303.5 & 297.9 & 15.1 & 14.3 \\
\hline Av. & 303.4 & 297.5 & 17.2 & 16.4 \\
\hline
\end{tabular}

sium, bicarbonate, and chloride in circulating erythrocytes averaged $-4 \mathrm{mM}(-24$ to +8$)$, $-0.1 \mathrm{mM}$ ( -0.9 to +0.9$),-1.1 \mathrm{mM}(-2.3$ to +1.5$)$ and $-1 \mathrm{mM}(-15$ to +6$)$, respectively. Thus only for total erythrocyte bicarbonate and chloride are there significant differences between the control experiments and the experiments in which hydrochloric acid was infused. Total circulating erythrocyte bicarbonate decreased $4 \mathrm{mM}$. Total circulating erythrocyte chloride increased $22 \mathrm{mM}$, equivalent to 12 per cent of the infused chloride.

Table III summarizes changes in osmolarity of plasma water contributed by the four monovalent ions, sodium, potassium, bicarbonate, and chloride, and changes in anion deficit $(\mathrm{Na}+\mathrm{K}-$ $\mathrm{Cl}-\mathrm{HCO}_{3}$ ) as a result of infusion of acid. Osmolarity decreased $5.9 \mathrm{mOsm}$. per liter. The difference between monovalent cations ( $\mathrm{Na}$ and $\mathrm{K})$ and monovalent anions $\left(\mathrm{HCO}_{3}\right.$ and $\mathrm{Cl}$ ) decreased $0.8 \mathrm{mEq}$. per liter, in part the resultant of an expected decrease in base binding of plasma proteins of $2 \mathrm{mEq}$. per liter as $\mathrm{pH}$ fell from 7.4 to 7.1 and an average increment in phosphate concentration of $0.5 \mathrm{mM}$ per liter following infusion of acid.

In the three control experiments in which there was no infusion, osmolarity contributed by monovalent ions decreased an average of $2.5 \mathrm{mOsm}$. per liter, and the anion deficit increased $1.6 \mathrm{mEq}$. per liter. 


\section{DISCUSSION}

In these experiments a large amount of strong acid containing a non-metabolizable, non-volatile anion whose distribution is largely extracellular has been infused over a short period of time. Under these conditions, 43 per cent of the infused acid is neutralized by extracellular bicarbonate as $\mathrm{CO}_{2}$ is eliminated by hyperventilation. Fifty-one per cent is neutralized by exchange of hydrogen ions for sodium ions and, to a lesser extent, potassium ions which diffuse into extracellular fluid along with water. In agreement with Van Slyke and Cullen (1) only about 18 per cent of the infused acid is neutralized by circulating blood.

\section{A. Validity of observed increase in extracellular fluid volume}

The validity of the observed increase in extracellular fluid volume following infusion of acid is crucial in interpreting the results of these experiments. Data sufficient to calculate this increase are presented in Figure 2. In each experiment the disappearance curve for radiosulfate was displaced to a lower range of concentrations. This displacement is considerably greater than that expected from the infusion of water equal in volume to the acid infused.

The observed expansion of extracellular fluid might be an artefact: a) If plasma sulfate concentration increased in acidosis enough to significantly lower measured radioactivity through selfabsorption; b) if in acidosis there is an increased permeability to radiosulfate of cell membranes or an increased diffusibility into extracellular fluid not included in the initial radiosulfate volume of distribution; or c) if edema fluid accumulating at operative sites after radiosulfate infusion but prior to acid infusion remains unequilibrated with plasma with the result that radiosulfate concentration in edema fluid exceeds that in well perfused areas.

The first source of error is eliminated by adding carrier sulfate in an amount one thousand times that in plasma samples taken for assaying radiosulfate activity. This is confirmed by the fact that recoveries of radiosulfate from plasma obtained after acid infusion are satisfactory. The second possible source of error is unlikely for the follow-

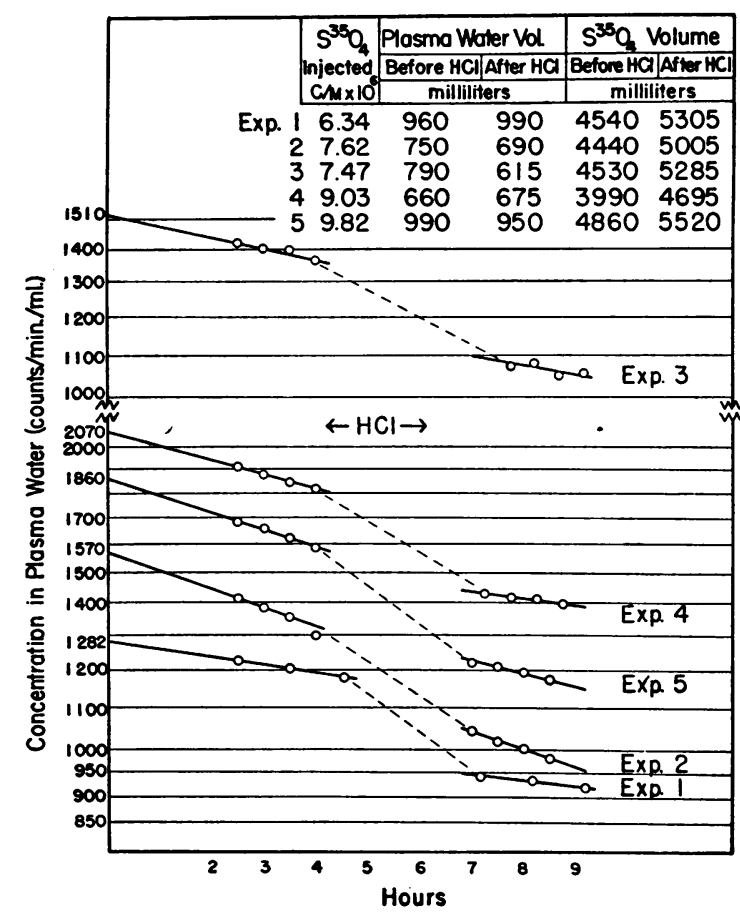

Fig. 2. Semilogarithmic Plot of Radiosulfate Concentration in Plasma Water Against Time Before and After Infusion of Hydrochloric Acid

ing reasons. Comparable increases in inulin volume of distribution (11) and in mannitol volume of distribution (12) have been observed after infusion of acid. The slope of the disappearance curve for radiosulfate remains unchanged or decreases slightly after acid infusion. In studies of respiratory acidosis and alkalosis under comparable experimental conditions, Giebisch, Berger, and Pitts (13) have observed no change in slope of the disappearance curve for radiosulfate as plasma $\mathrm{pH}$ varies from 6.8 to 7.8 . The third possible source of error is unlikely for the following reasons. No consistent differences in concentrations of monovalent ions or in the specific activity of radiochloride are seen between the two plasma samples obtained after acid infusion. The plot of the logarithm of radiosulfate concentration remains essentially linear after infusion of acid. We believe the increase in radiosulfate volume after the infusion of acid closely approximates the change in extracellular fluid volume.

However, the calculated increment in extracellular chloride in some experiments equals the amount of chloride infused and for all experiments 
the fraction of infused chloride transferred from the radiosulfate volume ( 6 per cent) is slightly less than the chloride calculated to have entered erythrocytes (equivalent to 12 per cent of infused chloride). This suggests that the calculated increment in extracellular fluid may be slightly in excess of the true increment. Such an error would mean that the fraction of infused acid neutralized by diffusion of sodium and potassium into extracellular fluid has been overestimated. It is not conceivable to us, however, that this error can be of such magnitude as to invalidate the conclusion that a large fraction of infused acid has been neutralized by transfer of sodium and potassium to extracellular fluid.

\section{B. Source of sodium and potassium transferred to extracellular fluid}

The source of the sodium and potassium transferred to extracellular fluid after acid infusion is not identified by these data, although certain inferences may be drawn from a consideration of change in total osmolarity of plasma contributed by the major monovalent ions.

The results of these experiments indicate that a significant fraction of chloride does not enter cells other than erythrocytes following hydrochloric acid infusion. Were this to occur, intracellular osmotic pressure might be expected to increase, with transfer of water to cells and contraction of extracellular fluid. Such a transfer has been described for erythrocytes (14) and is apparent in these data on erythrocyte water and ion content.

With infused chloride largely confined to extracellular fluid, it is conceivable that intracellular buffers participate in the neutralization of infused acid through a process in which intracellular sodium and potassium exchange for hydrogen ion $(11,15,16)$. The net effect would be the addition of sodium, potassium and chloride to extracellular fluid, a decrease in intracellular $\mathrm{pH}$ and a decrease in intracellular osmotic pressure due to the less ionized state of hydrogen, contrasted with sodium and potassium, in the presence of phosphate and proteinate. Calculations based on average values for the five experiments (Tables II and III), assuming an initial body water of 60 per cent of body weight and osmotic equilibrium between cells and extracellular fluid, support this possibility.
An $18.9 \mathrm{Kg}$. dog (Table II) has an initial body water of 11.4 liters, an initial radiosulfate volume of 4.47 liters (average of the five experiments) and an osmolarity of plasma water due to monovalent ions of $303.4 \mathrm{mOsm}$. per liter (Table III). One hundred and eighty $\mathrm{mM}$ (360 mOsm.) of hydrochloric acid in $615 \mathrm{ml}$. of water were infused into this average dog. Forty-three per cent of the infused hydrochloric acid is neutralized by extracellular bicarbonate. Acid thus neutralized does not effect a net increase in osmotically active solute since chloride merely replaces bicarbonate. Therefore, at most, only $205 \mathrm{mOsm}$. (360 - [360 X $0.43]$ ) have been added to body fluids.

Twenty-two $\mathrm{mM}$ of hydrochloric acid were apparently neutralized by erythrocyte buffers, approximately $4 \mathrm{mM}$ by bicarbonate and presumably $18 \mathrm{mM}$ by hemoglobin and phosphate, adding approximately $18 \mathrm{mOsm}$. to body fluids. If the fraction of infused acid neutralized by exchange of hydrogen ions for sodium and potassium ions had been neutralized entirely by bicarbonate outside the radiosulfate volume, the resulting osmolarity expected would be $289 \mathrm{mOsm}$. per liter.

11.4 L. $\times 303.4$ mOsm./L. $=3,455$ mOsm.

$(3,455$ mOsm. +18 mOsm. $) \div(11.4$ L. + 0.615 L. $)=289 \mathrm{mOsm}$.

If this fraction ( 51 per cent) had been neutralized by intracellular phosphate and proteinate buffers, with intracellular sodium and potassium ions exchanging for infused hydrogen ions, extracellular fluid would gain $184 \mathrm{mOsm}$. $(0.51 \times$ $360 \mathrm{mOsm}$.). Intracellular fluid would lose 92 mOsm. as weak acids of phosphate and proteinate replaced dissociated sodium and potassium salts of these anions. The net effect would be to increase osmolarity to:

$(3,455$ mOsm. +18 mOsm. +92 mOsm. $) \div$ $(11.4$ L. +0.615 L. $)=297$ mOsm./L. and extracellular fluid volume to 0.72 liter.

4.47 L. $\times 303.4 \mathrm{mOsm} . / \mathrm{L} .=1357 \mathrm{mOsm}$. (in extracellular fluid initially)

1,357 mOsm. +184 mOsm. $=1,541$ mOsm. (after infusion)

1,541 mOsm. $\div 297$ mOsm. $/$ L. $=5.19 \mathrm{~L}$.

5.19 L. -4.47 L. $=0.72 \mathrm{~L}$.

The osmolarity of plasma water (297.5 mOsm. per L., Table III) and the increment in radiosulfate volume $(0.715 \mathrm{~L}$., Table II) following acid infusion are in close agreement with the calculated 
values. These calculations do not consider some contribution to neutralization of acid by intracellular bicarbonate expected in these cationic transfers, a contribution which we are unable to estimate.

If sodium and potassium entering extracellular fluid to neutralize 51 per cent of infused acid had come from apatite crystals of bone by the reaction suggested by Bergstrom (17),

$-\mathrm{Ca}-\mathrm{O}-\mathrm{CO}_{2}-\mathrm{Na}+\mathrm{H}^{+}$Anion $\rightarrow-\mathrm{Ca}-$ Anion $+\mathrm{Na}^{+} \mathrm{HCO}_{3}^{-}$

The net effect would be replacement of $\mathrm{Na}^{+}$and $\mathrm{Cl}^{-}$for $\mathrm{H}^{+}$and $\mathrm{Cl}^{-}$in extracellular fluid and an increase in extracellular solute of $184 \mathrm{mOsm}$. without a concomitant change in osmotically active solute within cells. Osmolarity of plasma water expected after infusion of acid would be :

$(3,455$ mOsm. +18 mOsm. +184 mOsm. $) \div$ $(11.4$ L. +0.615 L. $)=304 \mathrm{mOsm} . / \mathrm{L}$.

The expected increase in extracellular fluid volume would be

$1,541 \mathrm{mOsm} . \div 304 \mathrm{mOsm} . / \mathrm{L} .=5.07 \mathrm{~L}$.

5.07 L. -4.47 L. $=0.60 \mathrm{~L}$.

That infused chloride is more than accounted for in erythrocytes and in the radiosulfate volume does not militate against this possibility since anion other than chloride might be substituted on the apatite crystal for sodium and carbonate (18).

These calculations ignore changes in water content of erythrocytes, changes in water and ion content of cerebrospinal fluid and perhaps gastrointestinal fluid, blood sampling and insensible water losses (19), factors which probably will not introduce important errors.

Combinations of the three possible mechanisms considered or of other mechanisms not considered could account for observed results. However, observed changes in extracellular fluid volume and plasma osmolarity agree closely with changes calculated by assuming that half of the infused acid is neutralized by exchange of extracellular hydrogen ions for intracellular sodium and potassium ions. This suggests that cells are the source of monovalent base entering extracellular fluid in acute acidosis rather than apatite crystals in bone as observed in more chronic, less severe, metabolic acidosis in rats (2).

Transfers of water, sodium, potassium, and hydrogen between cells and extracellular fluid of these magnitudes would reduce intracellular so- dium concentration by a degree consistent with that observed in analysis of muscle in metabolic acidosis (20). Such transfers would reduce intracellular water, $\mathrm{pH}$ and bicarbonate concentration, leaving intracellular potassium concentration essentially unchanged. Hastings and Eichelberger (21) and Cotlove, Holliday, Schwartz, and Wallace (20) calculated a slight increase in muscle cell water in metabolic acidosis and a slight increase in potassium concentration in muscle cell water (20). Wallace and Hastings (22) calculated that intracellular $\mathrm{pH}$ of muscle did not change significantly in metabolic acidosis and that intracellular bicarbonate concentration decreased only slightly. Thus in some respects the cation and water transfers proposed are inconsistent with available information on changes in muscle water and electrolytes in acidosis produced by hydrochloric acid administration.

The cation and water transfers suggested as responsible for the increase in extracellular sodium, potassium and water observed in these experiments on nephrectomized dogs may also follow hydrochloric acid infusion in the presence of renal function. However, it would be expected that increments in extracellular water, sodium, potassium, and chloride would not be maintained in the presence of renal function. When renal function is maintained, it is well known that metabolic acidosis is usually associated with a contracted extracellular fluid volume.

\section{Location of chloride not included in the radio- sulfate volume and in erythrocytes}

The increment in chloride in the radiosulfate volume and in erythrocytes accounts for slightly more than the chloride infused. Since the radiosulfate volume and erythrocytes contain only 80 to 85 per cent of the total body chloride (5), this would indicate that extracellular chloride concentration can increase 10 to 15 per cent without a corresponding increase in the amount of chloride located elsewhere than in the radiosulfate volume and in erythrocytes. While this suggests that 15 to 20 per cent of the total chloride may be either bound to extracellular solid structures or located intracellularly at unchanging concentration, it is probable that the methods are not sufficiently accurate to justify the conclusion that the magnitude 
of this smaller part of the total chloride did not change.

\section{SUMMARY}

Severe metabolic acidosis has been produced in nephrectomized dogs by infusing 9 to $10 \mathrm{mM}$ per $\mathrm{Kg}$. of hydrochloric acid over a period of two hours. Changes in total extracellular sodium, potassium, bicarbonate, and chloride have been calculated from plasma concentrations and changes in the radiosulfate volume of distribution. These changes indicate that approximately 40 per cent of the infused acid is neutralized by extracellular bicarbonate, approximately 10 per cent by erythrocyte buffers, and approximately 50 per cent by diffusion of sodium and potassium into extracellular fluid. Exchange of extracellular hydrogen ions for intracellular sodium and potassium ions is suggested to account for the increment in extracellular sodium and potassium.

\section{REFERENCES}

1. Van Slyke, D. D., and Cullen, G. E., Studies of acidosis. I. The bicarbonate concentration of the blood plasma; its significance, and its determination as a measure of acidosis. J. Biol. Chem., 1917, 30, 289.

2. Bergstrom, W. H., and Wallace, W. M., Bone as a sodium and potassium reservoir. J. Clin. Invest., 1954, 33, 867.

3. Pitts, R. F., and Swan, R. C., Fourth Conference on Renal Function. Bradley, S. E., ed., New York, Josiah Macy, Jr., Foundation. 1952, p. 22.

4. Swan, R. C., and Pitts, R. F., Neutralization of infused acid by the nephrectomized dog. Federation Proc., 1953, 12, 140.

5. Swan, R. C., Madisso, H., and Pitts, R. F., Measurement of extracellular fluid volume in nephrectomized dogs. J. Clin. Invest., 1954, 33, 1447.

6. Chinard, F. P., Estimation of plasma volume by dye dilution method in Methods in Medical Research. Visscher, M. B., ed., Chicago, Year Book Publishers, 1951, p. 38.

7. Van Slyke, D. D., and Neill, J. M., The determination of gases in blood and other solutions by vacuum extraction and manometric measurement. I. J. Biol. Chem., 1924, 61, 523.
8. Van Slyke, D. D., and Hiller, A., Application of Sendroy's iodometric chloride titration to proteincontaining fluids. J. Biol. Chem., 1947, 167, 107.

9. Van Slyke, D. D., and Hawkins, J. A., A gasometric method for determination of reducing sugars, and its application to analysis of blood and urine. J. Biol. Chem., 1928, 79, 739.

10. Pitts, R. F., The excretion of urine in the dog. VII. Inorganic phosphate in relation to plasma phosphate level. Am. J. Physiol., 1933, 106, 1.

11. Pitts, R. F., Mechanisms for stabilizing the alkaline reserves of the body. Harvey Lectures, 1952-53, 48, 172.

12. Swan, R. C., and Pitts, R. F., Unpublished observations.

13. Giebisch, G., Berger, L., and Pitts, R. F., The extrarenal response to acute acid-base disturbances of respiratory origin. J. Clin. Invest., 1955, 34, 231.

14. Van Slyke, D. D., Wu, H., and McLean, F. C., Studies of gas and electrolyte equilibria in the blood. V. Factors controlling the electrolyte and water distribution in the blood. J. Biol. Chem., 1923, 56, 765.

15. Cooke, R. E., and Segar, W. E., A proposed mechanism of extracellular regulation of muscle composition. Yale J. Biol. \& Med., 1952, 25, 83.

16. Schwartz, W. B., Jenson, R. L., and Relman, A. S., The disposition of acid administered to sodiumdepleted subjects: the renal response and the role of the whole body buffers. J. Clin. Invest., 1954, 33, 587.

17. Bergstrom, W. H., The relationship of sodium and potassium to carbonate in bone. J. Biol. Chem., 1954, 206, 711.

18. Bergstrom, W. H., Personal communication.

19. Miley, J. F., Contributions of urinary and insensible water losses to the dehydration of metabolic acidosis. Federation Proc., 1954, 13, 100.

20. Cotlove, E., Holliday, M. A., Schwartz, R., and Wallace, W. M., Effects of electrolyte depletion and acid-base disturbance on muscle cations. Am. J. Physiol., 1951, 167, 665.

21. Hastings, A. B., and Eichelberger, L., The exchange of salt and water between muscle and blood. I. The effect of an increase in total body water produced by the intravenous injection of isotonic salt solutions. J. Biol. Chem., 1937, 117, 73.

22. Wallace, W. M., and Hastings, A. B., The distribution of the bicarbonate ion in mammalian muscle. J. Biol. Chem., 1942, 144, 637. 